\title{
Tarsal Tunnel Syndrome
}

National Cancer Institute

\section{Source}

National Cancer Institute. Tarsal T unnel Syndrome. NCI Thesaurus. Code C85183.

A syndrome resulting from the entrapment and compression of the tibial nerve. Signs and symptoms include burning sensation, ting ling, and pain in the foot sole. 